\title{
Donor-acceptor type co-crystals of arylthio-substituted tetrathiafulvalenes and fullerenes
}

\author{
Xiaofeng Lu, Jibin Sun, Shangxi Zhang, Longfei Ma, Lei Liu, Hui Qi, Yongliang Shao \\ and Xiangfeng Shao*
}

\author{
Full Research Paper \\ Address: \\ State Key Laboratory of Applied Organic Chemistry, Lanzhou \\ University, Tianshui Southern Road 222, Lanzhou 730000, Gansu \\ Province, P. R. China \\ Email: \\ Xiangfeng Shao* - shaoxf@lzu.edu.cn \\ * Corresponding author \\ Keywords: \\ arylthio-substituted tetrathiafulvalene; co-crystal; donor-acceptor \\ system; fullerene
}

\author{
Beilstein J. Org. Chem. 2015, 11, 1043-1051. \\ doi:10.3762/bjoc.11.117 \\ Received: 08 February 2015 \\ Accepted: 01 June 2015 \\ Published: 19 June 2015 \\ This article is part of the Thematic Series "Tetrathiafulvalene chemistry". \\ Guest Editor: P. J. Skabara \\ (c) 2015 Lu et al; licensee Beilstein-Institut. \\ License and terms: see end of document.
}

\begin{abstract}
A series of donor-acceptor type co-crystals of fullerene (as the acceptor) and arylthio-substituted tetrathiafulvalene derivatives (Ar$\mathrm{S}-\mathrm{TTF}$, as the donor) were prepared and their structural features were thoroughly investigated. The formation of co-crystals relies on the flexibility of Ar-S-TTF and the size matches between Ar-S-TTF and fullerene. Regarding their compositions, the studied co-crystals can be divided into two types, where types I and II have donor:acceptor ratios of 1:1 and 1:2, respectively. Multiple intermolecular interactions are observed between the donor and acceptor, which act to stabilize the structures of the resulting co-crystals. In the type I co-crystals, the fullerene molecule is surrounded by four Ar-S-TTF molecules, that is, two Ar-S-TTF molecules form a sandwich structure with one fullerene molecule and the other two Ar-S-TTF molecules interact with the fullerene molecule along their lateral axes. In the type II co-crystals, one fullerene molecule has the donor-acceptor mode similar to that in type I, whereas the other fullerene molecule is substantially surrounded by the aryl groups on Ar-S-TTF molecules and the solvent molecules.
\end{abstract}

\section{Introduction}

Tetrathiafulvalene (TTF) [1-3] and its derivatives have attracted significant interest for decades. This is because this unique heterocycle system has provided most of the organic conductors possessing diverse electronic ground states [4-11]. Owing to their good electron donating ability and reversible electrochemical activity, TTF derivatives have recently been employed as building blocks for functional supramolecular systems [1222]. Among the TTF-based supramolecular systems, those involving fullerene molecules are of growing interest due to their potential application in organic voltaics [20]. The TTF-fullerene dyad is a typical donor-acceptor (D-A) system, where TTFs and fullerenes act as donors and acceptors, 
respectively. The TTF-fullerene dyad can be constructed by (1) connection of two components through covalent bonds [2327] or (2) supramolecular assembly between TTFs (as host) and fullerene (as guest) [28-41].

For the formation of the host-guest type supramolecular system, the shape and size complementarity between TTFs and fullerenes are key factors that give rise to the effective surface contact for the stabilization of the resulting supramolecular structures. Because pristine TTF cannot form good enough surface contact with fullerenes due to the shape and size mismatch [42], chemical modifications of TTF have been carried out. To this regard, introduction of substituents onto the peripheral sites [43-54] and expansion of the $\pi$-systems have been reported [55-59]. As reported, the $\pi$-extended TTFs (exTTF) can encapsulate fullerenes in solution, and form the inclusion complex with fullerenes as well [28-37]. Very recently, we have disclosed a facile approach toward the arylthio-substituted TTFs (hereafter denoted as Ar-S-TTF) [6062], which bear four aryl groups on the peripheral positions of the TTF core through the sulfur bridges. The Ar-S-TTF molecules are size and shape matched for fullerenes $\left(\mathrm{C}_{60} / \mathrm{C}_{70}\right)$, and the peripheral aryls show large rotational freedom that could adjust their spatial alignment to adapt to the environmental variations [61].

Regarding the structural feature of Ar-S-TTF, we have performed the complexation of Ar-S-TTFs with $\mathrm{C}_{60} / \mathrm{C}_{70}$, and found that Ar-S-TTF could form D-A type inclusion complexes with $\mathrm{C}_{60} / \mathrm{C}_{70}$ [63]. Crystallographic investigation reveals that the multidimensional interaction networks consisting of a central TTF core, peripheral aryls, and fullerenes are the key factors to stabilize the resulting supramolecular structures. Meanwhile, the solid state absorption study indicates that the inclusion complexes display a photoexcited electronic transition between $\mathrm{Ar}-\mathrm{S}-\mathrm{TTF}$ and $\mathrm{C}_{60} / \mathrm{C}_{70}$. To gain further insight into the structural features of Ar-S-TTF upon complexation with $\mathrm{C}_{60} / \mathrm{C}_{70}$, we have carried out the preparation a series of [(Ar-S-TTF)-(fullerene)] co-crystals and investigated their solid state structure, as reported herein. In this report we focus on the synthesis, composition (donor:acceptor ratio), and crystal structure of the resulting co-crystals.

\section{Results and Discussion Synthesis and compositions}

On the basis of hundreds of experimental runs, we found that the Ar-S-TTFs possessing the first redox potential $\left(E_{1 / 2}{ }^{1}\right)$ smaller than $0.6 \mathrm{~V}$ could form the co-crystal-type complexes with fullerene molecules $\mathrm{C}_{60}$ and/or $\mathrm{C}_{70}$, whereas those with $E_{1 / 2}{ }^{1}>0.6 \mathrm{~V}$ could not afford the desired complexes. The complexes obtained thus far are intrinsically neutral [63], which means the charge transfer does not take place between Ar-STTF and fullerenes in the ground state. In this regard, the $E_{1 / 2}{ }^{1}$ values of Ar-S-TTFs would not affect the formation of co-crystals. On the other hand, the interaction between the aryls and fullerene molecules is very important to stabilize the structure of the co-crystals as reported in the crystal structures section. For Ar-S-TTFs exhibiting $E_{1 / 2}{ }^{1}>0.6 \mathrm{~V}$, the aryl groups are more electron deficient than the phenyl $[61,62]$. The interaction between the electron-deficient aryls and fullerenes is weak; consequently, these TTFs $\left(E_{1 / 2}{ }^{1}>0.6 \mathrm{~V}\right)$ could not form the co-crystals with fullerenes.

Among the [(Ar-S-TTF)-(fullerene)] complexes obtained to this point, the complexes of Ar-S-TTFs 1-8 (Scheme 1) with $\mathrm{C}_{60} / \mathrm{C}_{70}$ were cropped in the single crystalline form, and the others were obtained as powdery samples with difficult to determine compositions. The [(Ar-S-TTF)-(fullerene)] co-crystals were prepared by evaporating the mixed solution of Ar-S-TTF and the corresponding fullerenes at room temperature. As a typical example, compound $1(12.8 \mathrm{mg}, 2 \mathrm{mmol})$ and $\mathrm{C}_{60}$ (7.2 $\mathrm{mg}, 1 \mathrm{mmol})$ were dissolved in carbon disulfide $\left(\mathrm{CS}_{2}\right.$, $7 \mathrm{~mL}$ ), and the resulting mixed solution was then placed in the dark hood and left standing without disruption. After 2 weeks, the black block-like single crystalline complex was cropped, and the composition of the complex was determined to be $\mathbf{1} \cdot\left(\mathrm{C}_{60}\right)_{2} \cdot\left(\mathrm{CS}_{2}\right)_{2}$ on the basis of the X-ray single crystal structure analysis. The synthetic conditions, compositions, yields, and morphologies for the 11 complexes are summarized in Table 1.

Concerning the compositions (donor:acceptor ratio), most of the co-crystals could be divided into two types (I and II), except for $\mathbf{2} \cdot\left(\mathrm{C}_{70}\right)_{4} \cdot(\mathrm{PhCl})_{2}$. The ratio of donor:acceptor (abbreviated as D:A) for the type I and type II co-crystals are 1:1 and 1:2, respectively. No solvent molecule was involved in most of the type I co-crystals, except for $4 \cdot \mathrm{C}_{60} \cdot \mathrm{CS}_{2}$, which contains a small, linear solvent, $\mathrm{CS}_{2}$. On the other hand, all of the type II co-crystals contain solvent molecules in their matrix. Since one Ar-STTF is capable of encapsulating a fullerene molecule [63], the larger ratio of fullerenes would result in the formation of additional void space by fullerene molecules, which could potentially accommodate the solvent molecules. In a previous report, we have proposed that $\mathrm{C}_{70}$ tends to form co-crystals with a larger acceptor ratio [63]. However, the present results suggest that this prediction would not hold because both $\mathrm{C}_{60}$ and $\mathrm{C}_{70}$ form the type I and type II co-crystals with Ar-S-TTFs as shown in Table 1. The D:A ratio for the co-crystals results from the cooperative effects of the geometry of Ar-S-TTF (particularly the peripheral aryls), the shape and size of the fullerene molecules, and the solvent molecules. Although we cannot presently provide a clear estimation of the D:A ratio of the 
<smiles>c1ccc(SC2=C(Sc3ccccc3)SC(=C3SC(Sc4ccccc4)=C(Sc4ccccc4)S3)S2)cc1</smiles>

1<smiles>COc1cccc(SC2=C(Sc3cccc(OC)c3)SC(=C3SC(Sc4cccc(OC)c4)=C(Sc4cccc(OC)c4)S3)S2)c1</smiles><smiles>c1ccc(SC2=C(Sc3ccccc3)SC(=C3SC(Sc4ccccn4)=C(Sc4ccccn4)S3)S2)cc1</smiles>

7<smiles>Cc1cccc(SC2=C(Sc3cccc(C)c3)SC(=C3SC(Sc4cccc(C)c4)=C(Sc4cccc(C)c4)S3)S2)c1</smiles>

2<smiles>Fc1cccc(SC2=C(Sc3ccccn3)SC(=C3SC(Sc4ccccn4)=C(Sc4ccccn4)S3)S2)n1</smiles>

5<smiles>c1ccc(SC2=C(Sc3ccccn3)SC(=C3SC(Sc4cccs4)=C(Sc4cccs4)S3)S2)nc1</smiles>

8<smiles>Cc1ccc(SC2=C(Sc3ccc(C)cc3)SC(=C3SC(Sc4ccc(C)cc4)=C(Sc4ccc(C)cc4)S3)S2)cc1</smiles>

3<smiles>c1cncc(SC2=C(Sc3cccnc3)SC(=C3SC(Sc4cccnc4)=C(Sc4cccnc4)S3)S2)c1</smiles>

Scheme 1: Chemical structures of Ar-S-TTFs 1-8.

Table 1: Experimental conditions for the preparation of the co-crystals.

\begin{tabular}{|c|c|c|c|c|c|}
\hline & Donor & Acceptor & Solvent $^{a}$ & Complex ${ }^{b}$ & Appearance \\
\hline \multirow{7}{*}{$\mathrm{C}_{60}$ complexes } & $\mathbf{1}, 12.8 \mathrm{mg}$ & $\mathrm{C}_{60}, 7.2 \mathrm{mg}$ & $\mathrm{CS}_{2}, 7 \mathrm{~mL}$ & $1 \cdot\left(\mathrm{C}_{60}\right)_{2} \cdot\left(\mathrm{CS}_{2}\right)_{2}, 7.3 \mathrm{mg}$ & Black block \\
\hline & $1,7 \mathrm{mg}$ & $\mathrm{C}_{60}, 5.7 \mathrm{mg}$ & $\mathrm{PhCl}, 6 \mathrm{~mL}$ & $1 \cdot\left(\mathrm{C}_{60}\right)_{2} \cdot \mathrm{PhCl}, 7.5 \mathrm{mg}$ & Black block \\
\hline & $2,6.9 \mathrm{mg}$ & $\mathrm{C}_{60}, 5.5 \mathrm{mg}$ & $\mathrm{PhCl}, 14 \mathrm{~mL}$ & $2 \cdot \mathrm{C}_{60}, 8.2 \mathrm{mg}$ & Black plate $^{c}$ \\
\hline & $4,34.1 \mathrm{mg}$ & $\mathrm{C}_{60}, 14.4 \mathrm{mg}$ & $\mathrm{CS}_{2}, 14 \mathrm{~mL}$ & $4 \cdot \mathrm{C}_{60} \cdot \mathrm{CS}_{2}, 29.2 \mathrm{mg}$ & Black block $^{\mathrm{C}}$ \\
\hline & $\mathbf{6}, 10 \mathrm{mg}$ & $\mathrm{C}_{60}, 11 \mathrm{mg}$ & $\mathrm{PhCl}, 9 \mathrm{~mL}$ & $\mathbf{6} \cdot\left(\mathrm{C}_{60}\right)_{2} \cdot(\mathrm{PhCl})_{2}, 17.1 \mathrm{mg}$ & Black block \\
\hline & $7,14.4 \mathrm{mg}$ & $\mathrm{C}_{60}, 5.5 \mathrm{mg}$ & $\mathrm{PhCl}, 12 \mathrm{~mL}$ & $7 \cdot \mathrm{C}_{60}, 8.8 \mathrm{mg}$ & Black plate \\
\hline & $\mathbf{8}, 14.6 \mathrm{mg}$ & $\mathrm{C}_{60}, 5.5 \mathrm{mg}$ & $\mathrm{PhCl}, 12 \mathrm{~mL}$ & $8 \cdot \mathrm{C}_{60}, 9.7 \mathrm{mg}$ & Black block \\
\hline \multirow{4}{*}{$\mathrm{C}_{70}$ complexes } & $1,9 \mathrm{mg}$ & $\mathrm{C}_{70}, 5.9 \mathrm{mg}$ & $\mathrm{PhCl}, 12 \mathrm{~mL}$ & $1 \cdot \mathrm{C}_{70}, 9.2 \mathrm{mg}$ & Black plate \\
\hline & $2,6.9 \mathrm{mg}$ & $\mathrm{C}_{70}, 4.2 \mathrm{mg}$ & $\mathrm{PhCl}, 10 \mathrm{~mL}$ & $2 \cdot\left(\mathrm{C}_{70}\right)_{4} \cdot(\mathrm{PhCl})_{2}, 6.1 \mathrm{mg}$ & Black prism \\
\hline & $3,13.8 \mathrm{mg}$ & $\mathrm{C}_{70}, 8.4 \mathrm{mg}$ & $\mathrm{PhCl}, 10 \mathrm{~mL}$ & $3 \cdot\left(\mathrm{C}_{70}\right)_{2} \cdot(\mathrm{PhCl})_{2}, 6 \mathrm{mg}$ & Black prism $^{\mathrm{c}}$ \\
\hline & $5,6.5 \mathrm{mg}$ & $\mathrm{C}_{70}, 4.2 \mathrm{mg}$ & $\mathrm{PhCl}, 8 \mathrm{~mL}$ & $5 \cdot \mathrm{C}_{70}, 4.1 \mathrm{mg}$ & Black block \\
\hline
\end{tabular}

${ }^{\mathrm{a}} \mathrm{CS}_{2}$ : carbon disulfide, $\mathrm{PhCl}$ : chlorobenzene; ${ }^{b}$ the compositions of the co-crystals were determined by $\mathrm{X}$-ray single crystal structure analysis; ${ }^{\mathrm{c}}$ see reference [63].

co-crystals, this work further demonstrates that Ar-S-TTFs are promising candidates to serve as receptors for fullerenes and have diverse supramolecular structures.

\section{Crystal structures}

The single crystalline structure of the complex is suitable for $\mathrm{X}$-ray single crystal diffraction measurements. In most cases, the fullerene molecules and solvent molecules are disordered. The disorder of fullerenes and solvents cannot be suppressed even at low temperature, and can thus be characterized as having statistic rather than rotational disorder. The selected crystallographic data are summarized in Tables S1 and S2 in Supporting Information File 1. In the following sections, the structures of the type I and type II co-crystals will be discussed in sequence.

\section{Type I co-crystals}

The type I co-crystals include four $\mathrm{C}_{60}$ complexes and two $\mathrm{C}_{70}$ complexes, namely, $2 \cdot \mathrm{C}_{60}, \mathbf{4} \cdot \mathrm{C}_{60} \cdot \mathrm{CS}_{2}, 7 \cdot \mathrm{C}_{60}, \mathbf{8} \cdot \mathrm{C}_{60}, \mathbf{1} \cdot \mathrm{C}_{70}$, and $5 \cdot \mathrm{C}_{70}$. It should be noted that we recently reported the structures of $\mathbf{2} \cdot \mathrm{C}_{60}$ and $\mathbf{4} \cdot \mathrm{C}_{60} \cdot \mathrm{CS}_{2}$ [63]. As a typical example of the newly obtained co-crystals, the structure of $\mathbf{5} \cdot \mathrm{C}_{70}$ is discussed 
here, and those of $7 \cdot \mathrm{C}_{60}, \mathbf{8} \cdot \mathrm{C}_{60}$, and $\mathbf{1} \cdot \mathrm{C}_{70}$ are provided in the Supporting Information File 1 (Figures S4-S15).

Complex $5 \cdot \mathrm{C}_{70}$ crystallizes in the triclinic space group $P-1$ with one molecule 5 and one $\mathrm{C}_{70}$ crystallographically unique (Figure 1a). The central TTF core on molecule $\mathbf{5}$ has a chair conformation. The molecular geometry of $\mathbf{5}$ in the co-crystal, both the spatial alignment of pyridyl groups and the conformation of the TTF core, is very close to its neutral crystalline form obtained in $\mathrm{CS}_{2}$ [61]. The $\mathrm{C}_{70}$ molecule is surrounded by four molecules 5 (Figure 1b), and the long axes of $\mathrm{C}_{70}$ and TTF5 are almost parallel to each other. A pair of 5 and a $\mathrm{C}_{70}$ molecule in a sandwich configuration is stabilized by multiple intermolecular atomic close contacts [64]: $\mathrm{C}-\mathrm{S}$ of 3.33-3.36 $\AA$ and $\mathrm{C}-\mathrm{C}$ of 3.17-3.40 $\AA$. The other two molecules of 5 have $\mathrm{C}-\mathrm{S}$ contacts $(3.23-3.50 \AA)$ with $\mathrm{C}_{70}$ along their lateral axes. Moreover, the $\mathrm{C}-\mathrm{C}$ contacts $(3.18-3.36 \AA)$ are also observed between the peripheral pyridyl groups and $\mathrm{C}_{70}$. Compound 5 and $\mathrm{C}_{70}$ form separated layers (Figures $\mathrm{S} 1-\mathrm{S} 3$ in Supporting Information File 1), and the arrangement of $\mathrm{C}_{70}$ molecules in the $a c$-plane is shown in Figure 1c. The center-tocenter distances between $\mathrm{C}_{70}$ molecules along the $(a-c)$ and $(a+c)$ directions are $10.2 \AA$ and $10.6 \AA$, respectively. The former is close to the short axis of $\mathrm{C}_{70}(10 \AA)$, thus $\mathrm{C}_{70}$ molecules form one-dimensional (1D) columnar arrays along this direction. The structural features for both donor-acceptor interaction mode and fullerene arrangement of $7 \cdot \mathrm{C}_{60}, \mathbf{8} \cdot \mathrm{C}_{60}$, and $\mathbf{1} \cdot \mathrm{C}_{70}$ are very similar to that of $\mathbf{5} \cdot \mathrm{C}_{70}$.

\section{Type II co-crystals}

Among the type II co-crystals, the structure of $\mathbf{3} \cdot\left(\mathrm{C}_{70}\right)_{2} \cdot(\mathrm{PhCl})_{2}$ has been reported [63]. Herein, we report the structures of $\mathbf{1} \cdot\left(\mathrm{C}_{60}\right)_{2} \cdot\left(\mathrm{CS}_{2}\right)_{2}$ and $\mathbf{1} \cdot\left(\mathrm{C}_{60}\right)_{2} \cdot \mathrm{PhCl}$, and that of $\mathbf{6} \cdot\left(\mathrm{C}_{60}\right)_{2} \cdot(\mathrm{PhCl})_{2}$ is provided in the Supporting Information File 1 (Figures S25-S29).

Complex $1 \cdot\left(\mathrm{C}_{60}\right)_{2} \cdot\left(\mathrm{CS}_{2}\right)_{2}$ crystallizes in the triclinic space group $P$-1. The asymmetric unit contains half a molecule of $\mathbf{1}$, two halves of $\mathrm{C}_{60}(\mathbf{A}$ and $\mathbf{B})$, and one $\mathrm{CS}_{2}$ molecule. The central $\mathrm{C}_{6} \mathrm{~S}_{4}$ moieties of both molecules $\mathbf{1}$ (A and $\mathbf{B}$ ) are nearly planar. Molecule $\mathbf{A}$ is disordered and surrounded by four molecules of $\mathbf{1}$. The donor-acceptor interaction mode for molecule $\mathbf{A}$ is very similar to those in type I co-crystals (Figure 2a): a pair of molecules of $\mathbf{1}$ forms a sandwich structure with $\mathbf{A}$ through multiple interactions (C-S, $3.50 \AA$; C-C, 3.20-3.38 $\AA$ ), and the other two molecules of $\mathbf{1}$ interact with $\mathbf{A}$ along their lateral axes. On the other hand, the $\mathrm{C}_{60}$ molecule $\mathbf{B}$ is ordered and surrounded by four phenyl groups with multiple $\mathrm{C}-\mathrm{C}$ contacts (3.19-3.38 $\AA$ ) as shown in Figure 2b. 1 and $\mathrm{C}_{60}$ form separated layers (Figures S16-S17 in Supporting Information File 1). The a)

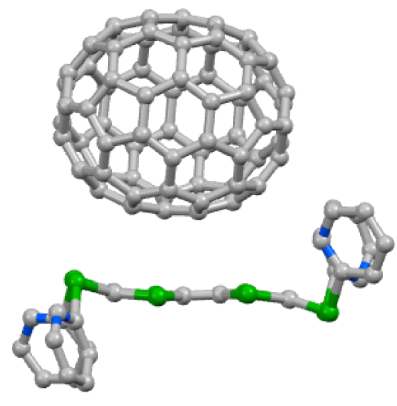

b)

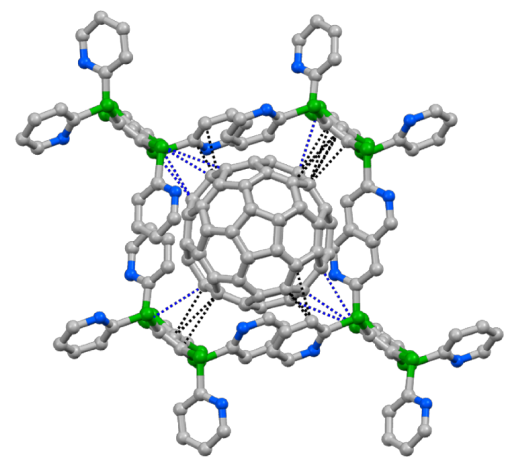

c)

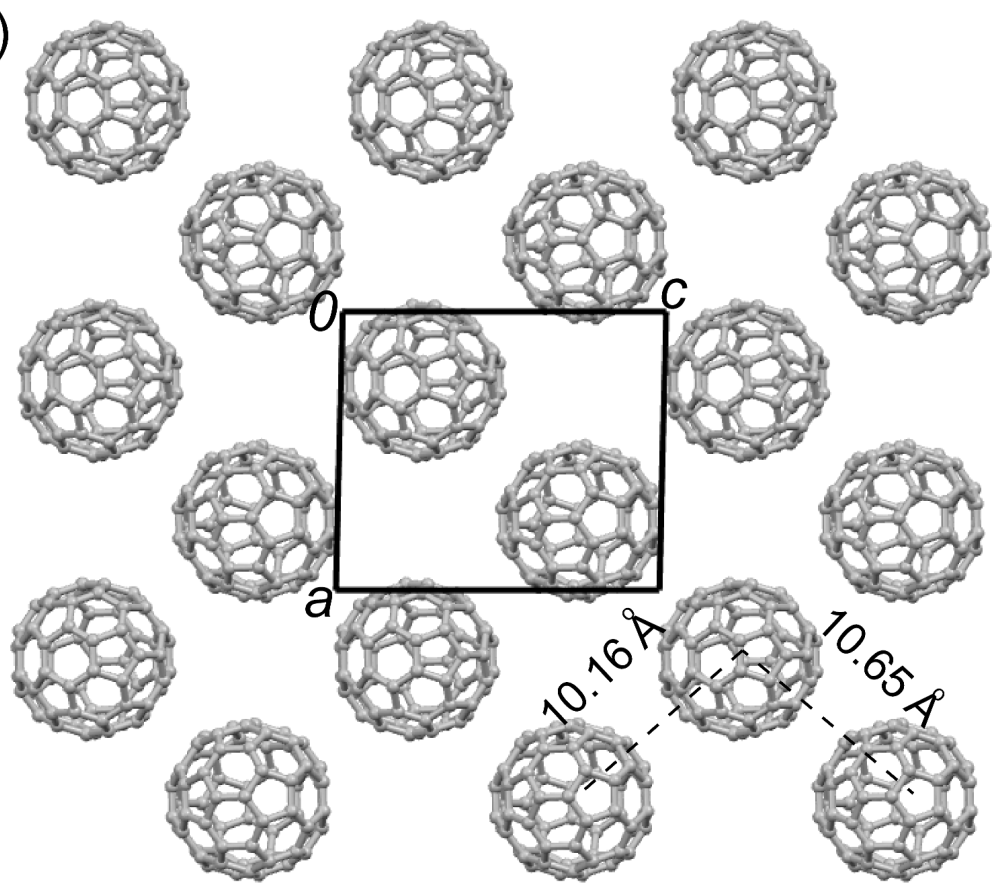

Figure 1: Crystal structure of $\mathbf{5} \cdot \mathrm{C}_{70}$. a) Unit cell contents viewed along the short axis of $\mathbf{5} ; \mathrm{b}$ ) Interactions between $\mathbf{5}$ and $C_{70}$, where the blue and black dashed lines represent the $\mathrm{C}-\mathrm{S}$ and $\mathrm{C}-\mathrm{C}$ contacts, respectively; $\mathrm{c}$ ) packing motif of $\mathrm{C}_{70}$ molecules viewed along the $b$-axis. The grey, blue and green spheres represent carbon, nitrogen and sulfur atoms, respectively, and the hydrogen atoms are omitted for clarity. 

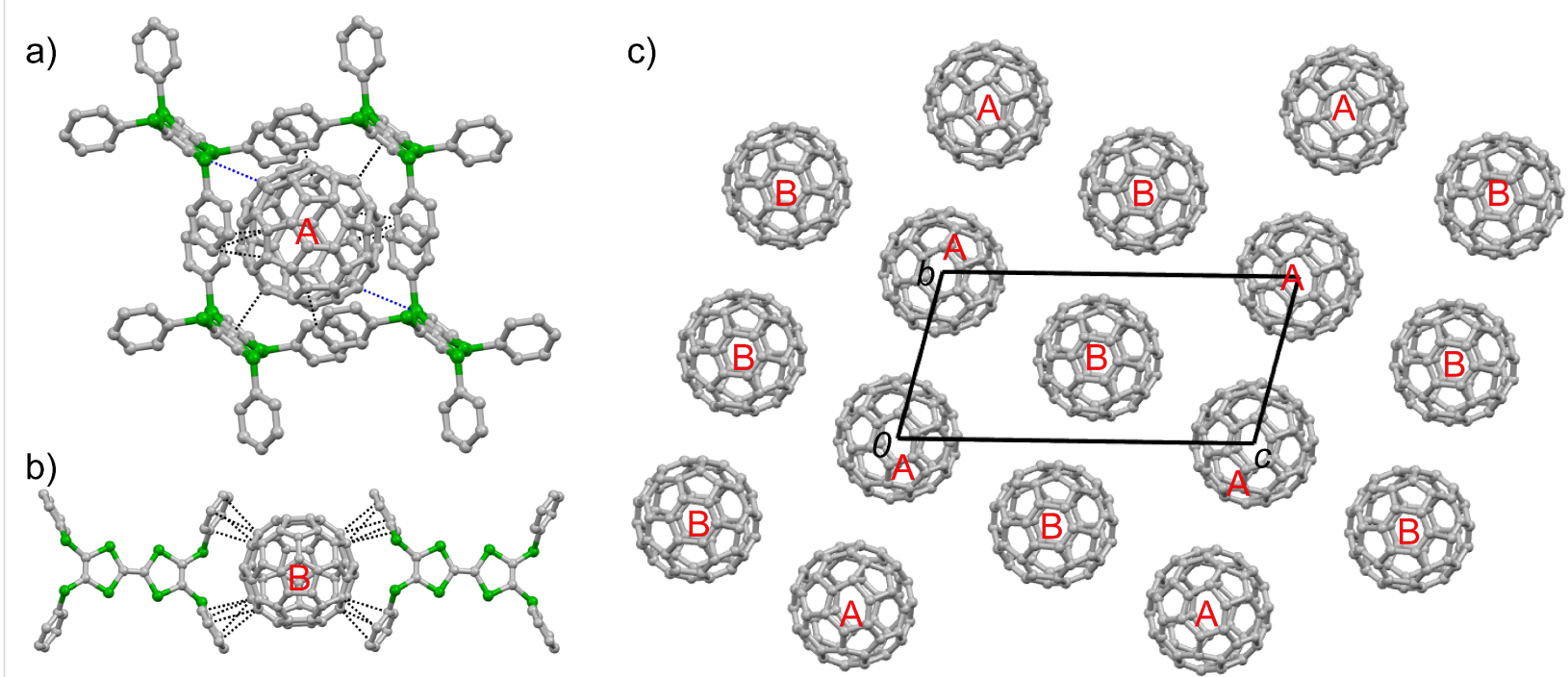

Figure 2: Crystal structure of $\mathbf{1} \cdot\left(\mathrm{C}_{60}\right)_{2} \cdot\left(\mathrm{CS}_{2}\right)_{2}$. a) Interactions of $\mathrm{C}_{60}$ molecule $\mathbf{A}$ with $\mathbf{1}$, where the blue and black dashed lines indicate the $\mathrm{C}-\mathrm{S}$ and $\mathrm{C}-\mathrm{C}$ contacts between 1 and $\mathrm{C}_{60}$, respectively. b) Interactions of $\mathrm{C}_{60}$ molecule $\mathrm{B}$ with $1 ; \mathrm{c}$ ) packing motifs of $\mathrm{C}_{60}$, depiction along the a-axis. The hydrogen atoms and solvent molecules are omitted for clarity.

a)

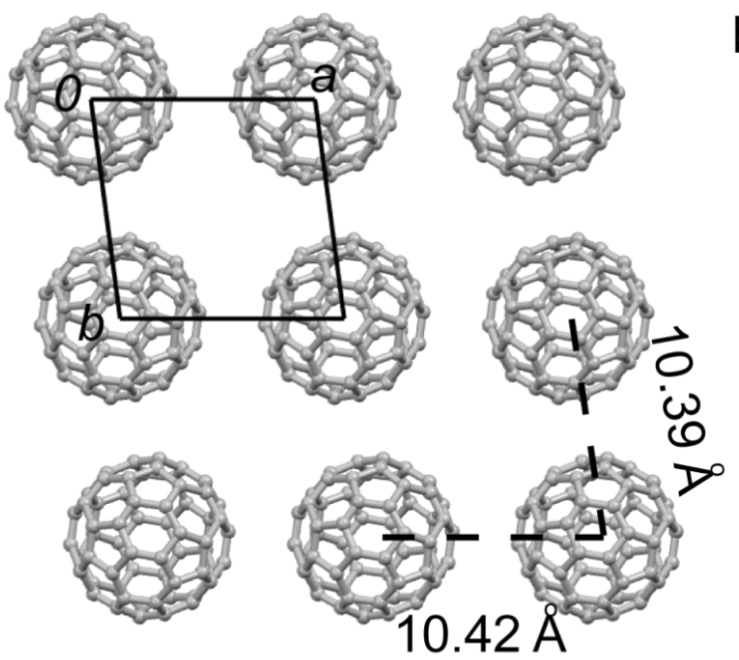

b)

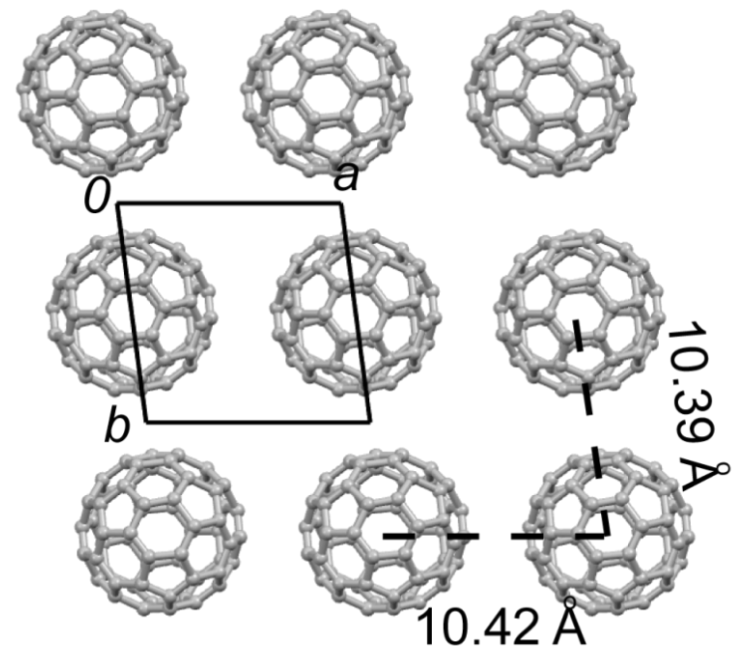

Figure 3: Packing motifs of $\mathrm{C}_{60}$ molecules $\mathbf{A}(\mathrm{a})$ and $\mathbf{B}(\mathrm{b})$ of $\mathbf{1} \cdot\left(\mathrm{C}_{60}\right)_{2} \cdot\left(\mathrm{CS}_{2}\right)_{2}$ in the crystallographic ab-plane with the center-to-center distance between the neighboring $\mathrm{C}_{60}$ molecules shown.

packing structure of $\mathrm{C}_{60}$ in the $b c$-plane is shown in Figure 2c. Molecules $\mathbf{A}$ and $\mathbf{B}$ form two kinds of two-dimensional (2D) sheets in the $a b$-plane as shown in Figure 3, and two sheets alternate along the $c$-axis. In both $2 \mathrm{D}$ sheets, the center-tocenter distances between adjacent $\mathrm{C}_{60}$ molecules are $10.4 \AA$ along the $a$ - and $b$-axes.

Complex $1 \cdot\left(\mathrm{C}_{60}\right)_{2} \cdot \mathrm{PhCl}$ crystallizes in the triclinic space group $P$-1. Unlike $1 \cdot\left(\mathrm{C}_{60}\right)_{2} \cdot\left(\mathrm{CS}_{2}\right)_{2}$, the asymmetric unit of $\mathbf{1} \cdot\left(\mathrm{C}_{60}\right)_{2} \cdot \mathrm{PhCl}$ contains one molecule of $\mathbf{1}$, four halves of $\mathrm{C}_{60}$
$(\mathbf{A}, \mathbf{B}, \mathbf{C}$, and $\mathbf{D})$, and one $\mathrm{PhCl}$ molecule. The central TTF core of $\mathbf{1}$ is in a planar conformation. As shown in Figure S18 in Supporting Information File $1, \mathbf{C}_{60}$ molecules $\mathbf{A}$ and $\mathbf{B}$ have a donor-acceptor interaction mode similar to those in the type I co-crystals, and several $\mathrm{C}-\mathrm{C}(3.17-3.39 \AA)$ and $\mathrm{C}-\mathrm{S}$ (3.46-3.49 $\AA$ ) contacts are observed between the central TTF core of 1 and $\mathrm{C}_{60}$ molecules. On the other hand, $\mathrm{C}_{60}$ molecules $\mathbf{C}$ and $\mathbf{D}$ are surrounded by the phenyl groups of $\mathbf{1}$ and solvent molecules $\mathrm{PhCl}$ (Figure S19 in Supporting Information File 1). The donor and acceptor molecules that form the separated 
layers are shown in Figures S20-S24 (Supporting Information File 1). Molecules $\mathbf{A}$ and $\mathbf{B}$ form a $2 \mathrm{D}$ sheet in the $a b$-plane (Figure S23 in Supporting Information File 1), where A and B form the different columnar arrays along the $a$-axis. The centerto-center distances between the adjacent $\mathrm{C}_{60}$ molecules are around $10.4 \AA$ along the $a$ - and $b$-axes. Molecules $\mathbf{C}$ and $\mathbf{D}$ also form the 2D sheet in the $a b$-plane (Figure S24 in Supporting Information File 1), and the configuration of the molecular arrays is similar to that in the $\mathbf{A B}$ sheet. The $\mathbf{A B}$ and $\mathbf{C D}$ sheets alternate along the crystallographic $c$-axis.

\section{Co-crystal $2 \cdot\left(\mathrm{C}_{70}\right)_{4} \cdot(\mathrm{PhCl})_{2}$}

This complex crystallizes in the monoclinic space group $C 2 / n$, and the asymmetric unit contains half of molecule 2 , two $\mathrm{C}_{70}$ molecules ( $\mathbf{A}$ and $\mathbf{B}$ ), and two halves of $\mathrm{PhCl}$ molecules. The central $\mathrm{C}_{6} \mathrm{~S}_{4}$ moiety of molecule $\mathbf{2}$ is nearly planar. In types I and II co-crystals, fullerene molecules are encapsulated by Ar-S-TTF molecules. However, in $\mathbf{2} \cdot\left(\mathrm{C}_{70}\right)_{4} \cdot(\mathrm{PhCl})_{2}$, molecule 2 penetrates into the void space formed by $\mathrm{C}_{70}$ molecules due to the large A:D ratio (4:1). Referring Figure 4, one molecule 2 is surrounded by six $\mathrm{C}_{70}$ neighbors. Along the longitudinal and lateral axes of molecule 2, four $\mathbf{A}$ molecules are located to show multiple donor-acceptor interactions (Figure 4a): $\mathrm{C}-\mathrm{C}$ contacts (3.22-3.37 $\AA$ ) between $p$-tolyl moieties and $\mathrm{C}_{70}$ along the longitudinal axis of 2 , and $\mathrm{C}-\mathrm{S}$ contacts $(3.44,3.47 \AA)$ between the central TTF core and $\mathrm{C}_{70}$ along the lateral axis of molecule 2 . On the other hand, two $\mathbf{B}$ molecules are located above and below the mean plane of 2 (Figure $4 \mathrm{~b}$ ), and there are $\mathrm{C}-\mathrm{S}$ (3.44-3.50 $\AA$ ) and $\mathrm{C}-\mathrm{C}(3.13,3.35 \AA)$ contacts between the $\mathrm{C}_{70}$ molecules and the central TTF core of 2 . The $\mathrm{C}_{70}$ molecules form the $3 \mathrm{D}$ network of the present co-crystals. As shown in Figure S30 Supporting Information File 1, one A molecule is surrounded by five $\mathbf{B}$ molecules, and one $\mathbf{B}$ molecule is surrounded by five A molecules. There are multiple $\mathrm{C}-\mathrm{C}$ close contacts (3.20-3.38 $\AA$ ) between the neighboring $\mathrm{C}_{70}$ molecules along the different directions, which result in the $3 \mathrm{D}$ carrier transport pathway [38-41].

\section{Structural comparison}

As has previously been reported, the van der Waals length of the $\mathrm{C}_{6} \mathrm{~S}_{8}$ core in the Ar-S-TTF molecule is about $12.8 \AA$ $[61,63]$, which is larger than the van der Waals diameters of $\mathrm{C}_{60}$ $(10 \AA)$ and $\mathrm{C}_{70}(11 \AA)[65,66]$. In this regard, a single Ar-STTF molecule is able to encapsulate $\mathrm{C}_{60} / \mathrm{C}_{70}$, and the size difference between $\mathrm{C}_{60}$ and $\mathrm{C}_{70}$ would not be the sole factor determining the composition of the co-crystal. The D:A ratio for the co-crystal is attributed to the cooperation of the geometry of the Ar-S-TTF (particularly the geometry and rotational freedom of the peripheral aryls), the shape and the size of the fullerene molecules, and the solvent molecules. Furthermore, the dynamic effect on the crystal growth is also taken into account.

Additionally, the D:A ratio of the co-crystal plays a significant role on the donor-acceptor interaction mode and the packing motif of the fullerenes. In the type I co-crystals ( $D: A=1: 1)$, the donor-acceptor interactions mainly exist between the central TTF core of the Ar-S-TTF and the fullerene molecules. Therefore, Ar-S-TTF serves as the host and the fullerene molecule is the guest. The fullerene molecules form the 1D columnar stacks with a center-to-center distance of around $10.3 \AA$, which is comparable with that of superconducting $\mathrm{C}_{60}$ complexes with alkali metals (e.g., $10.29 \AA$ in $\mathrm{RbCs}_{2} \mathrm{C}_{60}$ ) [67]. When the ratio of fullerene molecules increases (i.e., the type II co-crystals, $\mathrm{D}: \mathrm{A}=1: 2$ ), one fullerene molecule is substantially encapsulated by the central TTF core of Ar-S-TTF, and another

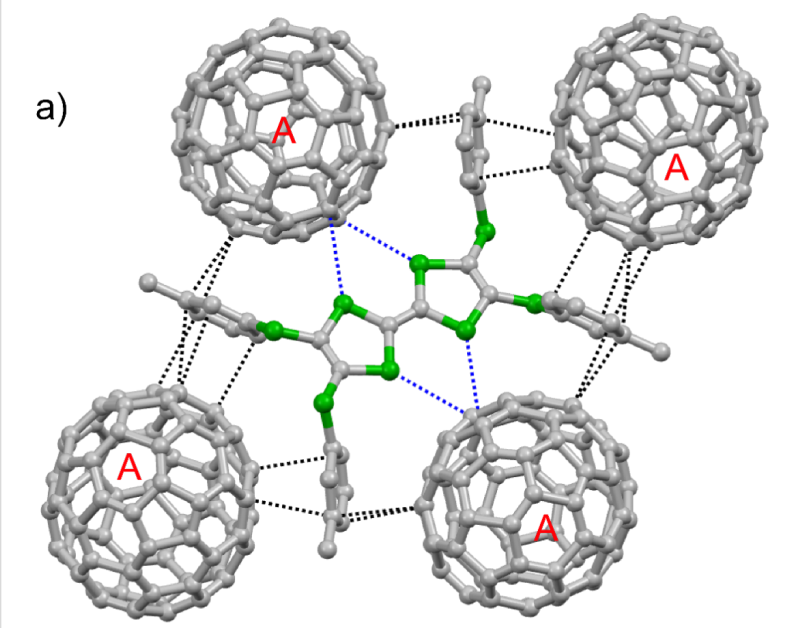

b)

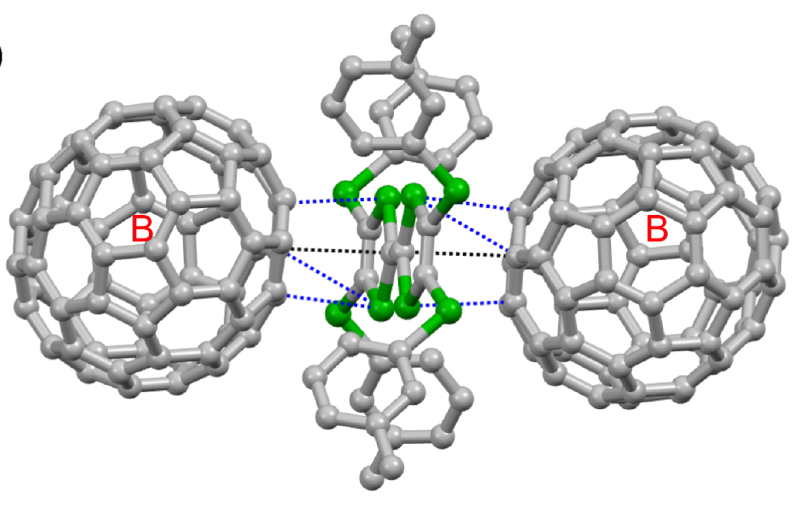

Figure 4: Crystal structure of 2. $\left(\mathrm{C}_{70}\right)_{4} \cdot(\mathrm{PhCl})_{2}$. a) Interactions between $\mathrm{C}_{70}$ molecule $\mathbf{A}$ and $\left.\mathbf{2} ; \mathrm{b}\right)$ Interactions between $\mathrm{C}_{70}$ molecule $\mathbf{B}$ and $\mathbf{2}$. The blue and black dashed lines indicated the intermolecular $\mathrm{C}-\mathrm{S}$ and $\mathrm{C}-\mathrm{C}$ contacts, respectively. The hydrogen atoms are omitted for clarity. 
fullerene molecule is surrounded by the aryls on the Ar-S-TTF and solvent molecules. In this case, the Ar-S-TTF molecule still acts as the host for at least one of the fullerene molecules. Moreover, the dimensionality of the packing motifs of fullerene molecules increases, resulting in a 2D network through multiple van der Waals forces. Upon further increase of the ratio of fullerene molecules in the co-crystal (e.g., $\left.2 \cdot\left(\mathrm{C}_{70}\right)_{4} \cdot(\mathrm{PhCl})_{2}\right)$, the packing structure becomes dominated by the $\mathrm{C}_{70}$ molecule, which forms the 3D network. The Ar-S-TTF and solvent molecules serve as the guests to occupy the void formed by the $\mathrm{C}_{70}$ molecules.

The present results demonstrate that Ar-S-TTF molecules have three key features that enable formation of donor-acceptor type co-crystals with fullerenes: (1) size and shape complementarity, (2) flexibility, and (3) the ability to introduce an additional interaction with fullerene by peripheral aryls. While the interactions between the TTF framework and fullerenes have been observed in many TTF-fullerene supramolecular systems [3841], the rotational freedom of the peripheral aryls on Ar-S-TTF causes the aryls to locate at the appropriate positions to form additional interactions with fullerenes. This therefore enhances the stability of the resulting co-crystals. By complexation with Ar-S-TTF molecules, the 1D columnar array, 2D sheets, and 3D networks of fullerene molecules have been successfully established, resulting in the carrier transport pathway, in principle. However, the ground state of the present co-crystals is intrinsically neutral, as demonstrated by the IR spectra (Figures S34-S40 in Supporting Information File 1). To improve the functionality of the co-crystals, one interesting strategy would be the generation of itinerant carriers in the co-crystals, i.e., charge transfer between the donor and acceptor in the ground state.

\section{Conclusion}

In summary, we have prepared eleven donor-acceptor type co-crystals of Ar-S-TTFs with fullerenes $\left(\mathrm{C}_{60} / \mathrm{C}_{70}\right)$, and performed thorough investigations on their solid state structures. These co-crystals mainly belong to two types according to the donor:acceptor ratios (D:A), types I and II having D:A of $1: 1$ and $1: 2$, respectively. The composition of the co-crystals is thought to be the cooperative consequence of the molecular geometry of Ar-S-TTF, the shape and size of the fullerene molecule, the solvent adduct, and the crystallization dynamics. The donor-acceptor interaction mode and the packing motif of the fullerenes largely depend on the composition of the co-crystal. The present results suggest that Ar-S-TTF molecules would be promising receptors for fullerenes as they are easily accessible. Meanwhile, Ar-S-TTFs possess the unique structural features to encapsulate fullerenes. That means the size matches with that of fullerenes and the flexibility is helpful to adapt to the shape of the fullerenes, which is supported by the additional stabilization force from the peripheral aryls moieties. Moreover, by varying the peripheral aryls and solvents, the 1D, $2 \mathrm{D}$, and $3 \mathrm{D}$ packing motifs of fullerenes can be selectively achieved.

\section{Supporting Information}

\section{Supporting Information File 1}

Additional experimental data.

[http://www.beilstein-journals.org/bjoc/content/ supplementary/1860-5397-11-117-S1.pdf]

\section{Supporting Information File 2}

Crystallographic data in CIF format.

[http://www.beilstein-journals.org/bjoc/content/

supplementary/1860-5397-11-117-S2.cif]

\section{Acknowledgements}

This work was financially supported by National Natural Science Foundation of China (21372111 and 21172104) and Research Fund for the Doctoral Program of Higher Education of China (RFDP 20120211110039).

\section{References}

1. Wudl, F.; Smith, G. M.; Hufnagel, E. J. J. Chem. Soc. D 1970, 1453. doi:10.1039/C29700001453

2. Coffen, D. L.; Chambers, J. Q.; Williams, D. R.; Garrett, P. E.; Canfield, N. D. J. Am. Chem. Soc. 1971, 93, 2258. doi:10.1021/ja00738a028

3. Hünig, S.; Kiesslich, G.; Scheutzow, D.; Zahradnik, R.; Carsky, P. Int. J. Sulfur Chem., Part C 1971, 6, 109. doi:10.1016/0368-2048(73)80012-X

4. Williams, J. M.; Ferraro, J. R.; Thorn, R. J.; Carlson, K. D.; Geiser, U.; Wang, H. H.; Kini, A. M.; Whangbo, M. H. Organic Superconductors (including Fullerenes); Prentice Hall: Englewood Cliffs, NJ, U.S.A., 1992.

5. Ishiguro, T.; Yamaji, K.; Saito, G. Organic Superconductors, 2nd ed.; Springer: Berlin, Germany, 1998.

6. Batail, P., Ed. Molecular Conductors. Chem. Rev. 2004, 104, 4887-5782.

7. Kagoshima, S.; Kanoda, K.; Mori, T., Eds. Organic Conductors. J. Phys. Soc. Jpn. 2006, 75, 051001-051802.

8. Lebed, A. The Physics of Organic Superconductors and Conductors; Springer: Berlin, Germany, 2008.

9. Ardavan, A.; Brown, S.; Kagoshima, S.; Kanoda, K.; Kuroki, K.; Mori, H.; Ogata, M.; Uji, S.; Wosnitza, J. J. Phys. Soc. Jpn. 2012, 81, 011004.

10. Ferraris, J.; Cowan, D. O.; Walatka, V.; Perlstein, J. H. J. Am. Chem. Soc. 1973, 95, 948. doi:10.1021/ja00784a066

11. Jérome, D.; Mazaud, A.; Ribault, M.; Bechgaard, K. J. Phys., Lett. 1980, 41, 95. doi:10.1051/jphyslet:0198000410409500

12. Bryce, M. R. Chem. Soc. Rev. 1991, 20, 355. doi:10.1039/CS9912000355 
13. Adam, M.; Müllen, K. Adv. Mater. 1994, 6, 439. doi:10.1002/adma.19940060603

14. Jørgensen, T.; Hansen, T. K.; Becher, J. Chem. Soc. Rev. 1994, 23 , 41. doi:10.1039/CS9942300041

15. Garian, J. Adv. Heterocycl. Chem. 1995, 62, 249. doi:10.1016/S0065-2725(08)60423-7

16. Coronado, E.; Gómez-García, C. J. Chem. Rev. 1998, 98, 273. doi:10.1021/cr970471c

17. Bryce, M. R. Adv. Mater. 1999, 11, 11. doi:10.1002/(SICI)1521-4095(199901)11:1<11::AID-ADMA11>3.0.CO; 2-3

18. Nielsen, M. B.; Lomholt, C.; Becher, J. Chem. Soc. Rev. 2000, 29, 153. doi:10.1039/A803992E

19. Segura, J. L.; Martín, N. Angew. Chem., Int. Ed. 2001, 40, 1372. doi:10.1002/1521-3773(20010417)40:8<1372::AID-ANIE1372>3.0.CO; 2-I

20. Bendikov, M.; Wudl, F.; Perepichka, D. F. Chem. Rev. 2004, 104, 4891. doi:10.1021/cr030666m

21. Frère, P.; Skabara, P. J. Chem. Soc. Rev. 2005, 34, 69. doi:10.1039/B316392J

22. Canevet, D.; Sallé, M.; Zhang, G.; Zhang, D.; Zhu, D. Chem. Commun. 2009, 2245. doi:10.1039/B818607N

23. Martín, N.; Sánchez, L.; Seoane, C.; Andreu, R.; Garín, J.; Orduna, J. Tetrahedron Lett. 1996, 37, 5979. doi:10.1016/0040-4039(96)01235-X

24. Martín, N.; Sánchez, L.; Herranz, M. Á.; Guldi, D. M. J. Phys. Chem. A 2000, 104, 4648. doi:10.1021/jp9941458

25. Giacalone, F.; Segura, J. L.; Martín, N.; Guldi, D. M. J. Am. Chem. Soc. 2004, 126, 5340. doi:10.1021/ja0318333

26. Fernández, G.; Pérez, E. M.; Sánchez, L.; Martín, N. Angew. Chem., Int. Ed. 2008, 47, 1094. doi:10.1002/anie.200703049

27. Fernández, G.; Pérez, E. M.; Sánchez, L.; Martín, N. J. Am. Chem. Soc. 2008, 130, 2410. doi:10.1021/ja710505h

28. Pérez, E. M.; Sánchez, L.; Fernández, G.; Martín, N. J. Am. Chem. Soc. 2006, 128, 7172. doi:10.1021/ja0621389

29. Pérez, E. M.; Sierra, M.; Sánchez, L.; Torres, M. R.; Viruela, R.; Viruela, P. M.; Ortí, E.; Martín, N. Angew. Chem., Int. Ed. 2007, 46, 1847. doi:10.1002/anie.200604327

30. Fernández, G.; Sánchez, L.; Pérez, E. M.; Martín, N J. Am. Chem. Soc. 2008, 130, 10674. doi:10.1021/ja8018498

31. Isla, H.; Gallego, M.; Pérez, E. M.; Viruela, R.; Ortí, E.; Martín, N. J. Am. Chem. Soc. 2010, 132, 1772. doi:10.1021/ja910107m

32. Huerta, E.; Isla, H.; Pérez, E. M.; Bo, C.; Martín, N.; de Mendoza, J. J. Am. Chem. Soc. 2010, 132, 5351. doi:10.1021/ja1006993

33. Grimm, B.; Santos, J.; Illescas, B. M.; Muñoz, A.; Guldi, D. M.; Martín, N. J. Am. Chem. Soc. 2010, 132, 17387. doi:10.1021/ja108744a

34. Canevet, D.; Gallego, M.; Isla, H.; de Juan, A.; Pérez, E. M.; Martín, N J. Am. Chem. Soc. 2011, 133, 3184. doi:10.1021/ja111072j

35. Fukuzumi, S.; Ohkubo, K.; Kawashima, Y.; Kim, D. S.; Park, J. S.; Jana, A.; Lynch, V. M.; Kim, D.; Sessler, J. L. J. Am. Chem. Soc. 2011, 133, 15938. doi:10.1021/ja207588c

36. Zhou, Z.; Qin, Y.; Xu, W.; Zhu, D. Chem. Commun. 2014, 50, 4082. doi:10.1039/c4cc00741g

37. Nielsen, K. A.; Cho, W.-S.; Sarova, G. H.; Petersen, B. M.; Bond, A. D.; Becher, J.; Jensen, F.; Guldi, D. M.; Sessler, J. L.; Jeppesen, J. O. Angew. Chem., Int. Ed. 2006, 45, 6848. doi:10.1002/anie.200602724

38. Izuoka, A.; Tachikawa, T.; Sugawara, T.; Suzuki, Y.; Konno, M.; Saito, Y.; Shinohara, H. J. Chem. Soc., Chem. Commun. 1992, 1472. doi:10.1039/C39920001472
39. Konarev, D. V.; Semkin, V. N.; Graja, A.; Lyubovskaya, R. N J. Mol. Struct. 1998, 450, 11. doi:10.1016/S0022-2860(98)00408-6

40. Saito, G.; Sasaki, H.; Aoki, T.; Yoshida, Y.; Otsuka, A.; Yamochi, H.; Drozdova, O. O.; Yakushi, K.; Kitagawa, H.; Mitani, T. J. Mater. Chem. 2002, 12, 1640. doi:10.1039/B110605H

41. Konarev, D. V.; Khasanov, S. S.; Saito, G.; Otsuka, A.; Lyubovskaya, R. N. J. Mater. Chem. 2007, 17, 4171. doi:10.1039/B704371F

42. Pérez, E. M.; Marín, N. Chem. Soc. Rev. 2008, 37, 1512. doi:10.1039/B802589B

43. Yamada, J.; Sugimoto, T., Eds. TTF Chemistry: Fundamentals and Applications of Tetrathiafulvalenes; Springer: Berlin, Germany, 2004.

44. Hervé, K.; Liu, S.-X.; Cador, O.; Golhen, S.; Gal, Y. L.; Bousseksou, A.; Stoeckli-Evans, H.; Decurtins, S.; Ouahab, L. Eur. J. Inorg. Chem. 2006, 3498. doi:10.1002/ejic.200600351

45. Jia, C.; Liu, S.-X.; Tanner, C.; Leiggener, C.; Neels, A.; Sanguinet, L.; Levillain, E.; Leutwyler, S.; Hauser, A.; Decurtins, S. Chem. - Eur. J. 2007, 13, 3804. doi:10.1002/chem.200601561

46. Murata, T.; Morita, Y.; Yakiyama, Y.; Fukui, K.; Yamochi, H.; Saito, G.; Nakasuji, K. J. Am. Chem. Soc. 2007, 129, 10837. doi:10.1021/ja072607m

47. Zhu, Q.-Y.; Liu, Y.; Lu, W.; Zhang, Y.; Bian, G.-Q.; Niu, G.-Y.; Dai, Y. Inorg. Chem. 2007, 46, 10065. doi:10.1021/ic700672e

48. Wu, J.-C.; Liu, S.-X.; Keene, T. D.; Neels, A.; Mereacre, V.; Powell, A. K.; Decurtins, S. Inorg. Chem. 2008, 47, 3452. doi:10.1021/ic800138x

49. Fujiwara, H.; Sugishima, Y.; Tsujimoto, K. Tetrahedron Lett. 2008, 49, 7200. doi:10.1016/j.tetlet.2008.10.001

50. Zhu, Q.-Y.; Huo, L.-B.; Qin, Y.-R.; Zhang, Y.-P.; Lu, Z.-J.; Wang, J.-P.; Dai, J. J. Phys. Chem. B 2010, 114, 361. doi:10.1021/jp908399r

51. Jaggi, M.; Blum, C.; Marti, B. S.; Liu, S.-X.; Leutwyler, S.; Decurtins, S. Org. Lett. 2010, 12, 1344. doi:10.1021/ol1002708

52. Mitamura, Y.; Yorimitsu, H.; Oshima, K.; Osuka, A. Chem. Sci. 2011, 2, 2017. doi:10.1039/C1SC00372K

53. Lincke, K.; Frellsen, A. F.; Parker, C. R.; Bond, A. D.; Hammerich, O.; Nielsen, M. B. Angew. Chem., Int. Ed. 2012, 51, 6099. doi:10.1002/anie.201202324

54. Ueno, R.; Fujino, D.; Yorimitsu, H.; Osuka, A. Chem. - Eur. J. 2013, 19, 7156. doi:10.1002/chem.201300623

55. Yamashita, Y.; Kobayashi, Y.; Miyashi, T. Angew. Chem., Int. Ed. Engl. 1989, 28, 1052. doi:10.1002/anie.198910521

56. Christensen, C. A.; Batsanov, A. S.; Bryce, M. R. J. Org. Chem. 2007, 72, 1301. doi:10.1021/jo062199p

57. Kato, T.; Origuchi, C.; Shinoda, M.; Adachi, C. Jpn. J. Appl. Phys. 2011, 50, 050202. doi:10.1143/JJAP.50.050202

58. Yamashita, M.; Kuzuhara, D.; Aratani, N.; Yamada, H. Chem. - Eur. J. 2014, 20, 6309. doi:10.1002/chem.201304997

59. Nielsen, K. A.; Cho, W.-S.; Jeppesen, J. O.; Lynch, V. M.; Becher, J.; Sessler, J. L. J. Am. Chem. Soc. 2004, 126, 16296. doi:10.1021/ja044664a

60. Sun, J.; Lu, X.; Shao, J.; Cui, Z.; Shao, Y.; Jiang, G.; Yu, W.; Shao, X. RSC Adv. 2013, 3, 10193. doi:10.1039/C3RA41349G

61.Sun, J.; Lu, X.; Shao, J.; Li, X.; Zhang, S.; Wang, B.; Zhao, J.; Shao, Y.; Fang, R.; Wang, Z.; Yu, W.; Shao, X. Chem. - Eur. J. 2013, 19, 12517. doi:10.1002/chem.201301819

62. Lu, X.; Sun, J.; Liu, Y.; Shao, J.; Ma, L.; Zhang, S.; Zhao, J.; Shao, Y.; Zhang, H.-L.; Wang, Z.; Shao, X. Chem. - Eur. J. 2014, 20, 9650. doi:10.1002/chem.201402327 
63. Sun, J.; Lu, X.; Ishikawa, M.; Nakano, Y.; Zhang, S.; Zhao, J.; Shao, Y.; Wang, Z.; Yamochi, H.; Shao, X. J. Mater. Chem. C 2014, 2, 8017. doi:10.1039/c4tc01362j

64. Bondi, A. J. Phys. Chem. 1964, 68, 441. doi:10.1021/j100785a001

65. Krätschmer, W.; Lamb, L. D.; Fostiropoulos, K.; Huffman, D. R. Nature 1990, 347, 354. doi:10.1038/347354a0

66. Hawkins, J. M.; Lewis, T. A.; Loren, S. D.; Meyer, A.; Heath, J. R.; Saykally, R. J.; Hollander, F. J. J. Chem. Soc., Chem. Commun. 1991, 775. doi:10.1039/C39910000775

67. Tanigaki, K.; Prassides, K. J. Mater. Chem. 1995, 5, 1515. doi:10.1039/JM9950501515

\section{License and Terms}

This is an Open Access article under the terms of the Creative Commons Attribution License

(http://creativecommons.org/licenses/by/2.0), which permits unrestricted use, distribution, and reproduction in any medium, provided the original work is properly cited.

The license is subject to the Beilstein Journal of Organic Chemistry terms and conditions:

(http://www.beilstein-journals.org/bjoc)

The definitive version of this article is the electronic one which can be found at: doi:10.3762/bjoc. 11.117 